\title{
O USO DAS TECNOLOGIAS DIGITAIS ENTRE OS SENIORES Motivações e interesses
}

\author{
Isabel Dias
}

\section{Introdução}

A velhice como estado do indivíduo supõe uma etapa da vida: a última. Numa perspetiva mais ampla, o envelhecimento é um largo processo que ocorre desde o nascimento até à morte.

Velho, velhice, envelhecimento fazem referência a uma condição temporal e mais concretamente a uma forma de ter em conta o tempo e suas consequências no indivíduo. Com frequência considera-se que é a idade cronológica de um indivíduo que marca a velhice. Esta não só se estabelece em função da idade, como também a idade física é um potencial indicador da velhice. Todavia, a idade cronológica apenas explica parcialmente o processo de envelhecimento (Fonseca, 2004).

O processo de envelhecimento comporta três componentes (biológica, social e psicológica), que correspondem, por seu turno, a três tipos de idades, nomeadamente a idade biológica (refere-se ao funcionamento dos sistemas vitais do organismo e à sua vulnerabilidade crescente, à medida que declinam as capacidades de autorregulação), a sociocultural (relativa aos papéis sociais apropriados às expectativas da sociedade para esta categoria social) e a psicológica (refere-se às capacidades de natureza psicológica e comportamentais do indivíduo necessárias para se adaptar ao meio envolvente) (Fonseca, 2004: 24; Paúl, 1997). Não é, por isso, produto de um único conjunto de determinantes, pelo contrário, o envelhecimento é consequência da nossa base filogenética, da nossa hereditariedade única, do meio físico e social no qual as predisposições genéticas se exprimem, do pensamento e das nossas escolhas (Paúl, 1997).

O ser humano experimenta uma série de mudanças ao longo da vida. Após uma etapa relativamente curta de desenvolvimento físico (coincidente com a infância e a adolescência), chega-se a uma fase, prolongada, em que gradualmente as nossas capacidades físicas vão entrando em declínio. Apesar de ser certo, em termos gerais, que com o tempo o organismo é menos eficiente, existem certos padrões de estabilidade e mudança. Porém, observa-se uma grande variabilidade entre as pessoas ao nível do seu processo de envelhecimento.

Em todo o caso, o conceito de velhice deficitária provém claramente da velhice física ou biológica. Mas existem outros conceitos de velhice, associados às componentes de envelhecimento anteriormente descritas, nomeadamente a velhice psicológica e social.

No primeiro caso, existem mudanças psicológicas que se produzem ao longo da vida, mas pode-se dizer que o envelhecimento psicológico resulta de um equilíbrio entre estabilidade e mudança e também entre crescimento e declínio. Por outras 
palavras, existem funções que, a partir de certa idade, estabilizam (e.g., a maior parte das variáveis de personalidade); outras, na ausência de doença, experimentam um crescimento ao longo do ciclo vital (e.g., a experiência e os conhecimentos); e outras ainda declinam e comportam-se isomorficamente, como a chamada idade física (e.g., a inteligência fluida, o tempo de reação) (Paúl, 1997).

Por último, a sociedade estabelece determinados papéis para distintas idades. Daí podermos falar de uma idade social da velhice. Ao encontrar-se regulada com base na idade laboral, considera-se que ela começa com a reforma (Esteves, 1995).

A relação entre idade e mercado de trabalho é uma componente crucial da criação do status social de dependente na idade avançada. Este estatuto tem vindo a ser reforçado com a intervenção do Estado, quer através da institucionalização da reforma, quer através da sua antecipação, o que começou a suceder por volta dos anos 1980. Todavia, ao creditar-se excessivamente o critério cronológico como mecanismo de definição da idade avançada, fica obscurecido o processo através do qual os indivíduos com uma determinada idade passam a ter acesso a um conjunto de recursos (Mendes, 2005).

Viver e envelhecer são assim fenómenos imbuídos do estado cultural, social, político, económico e tecnológico de uma sociedade. As sociedades do conhecimento ou da informação, como as atuais, definiram novas possibilidades e limites para os idosos. Com a introdução das tecnologias da informação e da comunicação (TIC), mudou o modo de acesso e produção de conhecimento. O uso destas tecnologias tornou-se, nas sociedades em rede, não só num imperativo dos sistemas de ensino-aprendizagem, como condição de inclusão de todos os cidadãos. A educação ao longo da vida surge, para os mais velhos, como forma de acesso à formação e informação (Cardoso e outros, 2005). Estes, por força dos efeitos de geração, correm riscos superiores de exclusão das ditas sociedades.

A velhice é assim uma construção social, para a qual contribui um conjunto de políticas voltadas especificamente para esta população. Nas sociedades atuais tais políticas, sejam de emprego, saúde, lazer ou no domínio das tecnologias da informação e da comunicação, têm vindo a contribuir para a representação da pessoa idosa como uma categoria social ora dependente, ora tecnologicamente excluída (Dias, 2005: 249).

A velhice implica simultaneamente dimensões pessoais e sociais e afeta principalmente pessoas adultas. Nas nossas sociedades, ela converteu-se numa preocupação social que afeta pessoas de todas as idades. Também passou a estar no centro da atenção de profissionais de vários campos disciplinares. De qualquer modo, a forma como uma sociedade caracteriza a velhice define em grande medida as condições sociais e institucionais nas quais as pessoas mais velhas vivem. A forma como se trata as pessoas mais velhas, os recursos económicos de que se dispõe e os meios institucionais que se põem em prática, assim como os programas de apoio, de lazer e de inclusão (inclusive digital) refletem a ideia social compartilhada da experiência de ser mais velho.

Por último, a importância da velhice, do seu estudo e intervenção decorre do crescimento deste grupo social, mas não apenas. Em primeiro lugar, a idade, critério 
métrico fundamental, só tem uma função referencial. A idade não é causa das mudanças que ocorrem num grupo, mas um indicador do que pode vir a acontecer às pessoas situadas num determinado grupo cronológico (Fonseca, 2004). Porém, são diferentes as circunstâncias pessoais, familiares e sociais de cada indivíduo situado nesse mesmo grupo.

Em segundo lugar, a velhice adquiriu maior importância, devido ao incremento da noção de que as pessoas mais velhas são um grupo distinto e definitório. Enquanto tal, os mais velhos tendem a agrupar-se. Esta tendência revela que os idosos interagem uns com os outros e fazem-no de forma a fazer parte de um grupo social em relação ao qual têm categorias e elementos de definição implícitos e explícitos. Tendo em consideração todos estes elementos podemos definir a velhice simultaneamente como uma etapa da vida, uma categoria (não uniforme) e um grupo social.

O envelhecimento demográfico afeta as sociedades desenvolvidas em todas as suas dimensões (e.g., organização do trabalho, tempos sociais, etc.). Encontrando-se o ciclo de vida definido pelas atividades educativas e formativas de preparação para o trabalho e para a profissão, nestas sociedades o Estado de bem-estar social tem excluído o idoso/reformado do "mundo social ativo". O tempo do "reformado" passou a ser definido pelo tempo livre e pelo lazer enquanto atividade não profissional (Esteves, 1995: 111).

No contexto de envelhecimento demográfico europeu, o equilíbrio entre gerações é cada vez mais crítico. Perante o processo planetário de envelhecimento, os governos europeus proclamam novas oportunidades para os mais jovens, ao mesmo tempo que se preocupam com o envelhecimento em atividade para os mais velhos (Mendes, 2005: 1). Esta preocupação é tanto maior quanto a sociedade atual é, segundo Castells (2007), uma sociedade em rede. Tal significa que a sociedade é formada por redes de poder, riqueza, gestão e comunicação na trama da estrutura social. Significa também que é constituída por pessoas que, individual ou coletivamente, se vão apropriando do poder comunicador da internet para gerar novas formas de vida, sociabilidade e alternativas políticas. Com efeito, quando nos anos 1970 se constituiu um novo paradigma tecnológico, organizado em torno da tecnologia da informação, principalmente nos Estados Unidos da América, foi, de igual modo, um novo estilo de comunicação, de gestão e de viver que se concretizou (Castells, 2007: 6).

A partir dos anos 1990 a sociedade em rede intensifica-se e as tecnologias da informação e da comunicação expandem-se a milhões de pessoas em todo o mundo, as quais percebem que através delas são ilimitadas as possibilidades de construírem as suas próprias redes instrumentais e sociais (Castells, em Cardoso e outros, 2005: 27-28). O novo paradigma da tecnologia da informação fornece assim as bases materiais para a expansão da sua penetrabilidade em toda a estrutura social. "As redes constituem a nova morfologia das sociedades e a difusão da sua lógica modifica substancialmente as operações e os resultados dos processos de produção, experiência, poder e cultura" (Castells, 2007: 605). De tal modo que a presença ou ausência na rede são fatores críticos de inclusão ou exclusão, tal como sucede com a população sénior. 
Com base no levantamento de dados recolhidos a partir de um inquérito administrado a utilizadores de espaços de internet e frequentadores de centros de emprego das cidades de Lisboa, Porto e Coimbra, e de entrevistas realizadas no âmbito do projeto de investigação Inclusão e Participação Digital, ${ }^{1}$ pretende-se, no presente artigo, analisar a relação dos seniores mais jovens (55-65 anos) e dos mais velhos (com mais de 66 anos) com as tecnologias digitais, em particular com o computador e a internet. Para além de se analisar as suas motivações e interesses visa-se, de igual modo, compreender em que medida o uso de tecnologias da informação e da comunicação se inscreve na noção de formação ao longo da vida, contribui para a inclusão (ou não) dos mais velhos nas sociedades tecnológicas e incrementa as relações e solidariedades intergeracionais e amicais.

O artigo é composto por um enquadramento teórico, com vista a dar conta dos conceitos norteadores da presente análise, nomeadamente envelhecimento ativo, envelhecimento produtivo, formação ao longo da vida, sociedade em rede, inclusão digital, entre outros. Segue-se a explicitação dos procedimentos metodológicos, dos resultados e sua discussão.

\section{Envelhecimento ativo e produtivo: os novos papéis dos seniores nas sociedades tecnológicas}

O início do século $X X$ foi marcado pela emergência de uma imagem de velhice fortemente negativa devido à sua improdutividade. O progresso científico e tecnológico veio despojar as pessoas idosas dos seus papéis e do prestígio social que as rodeava nas sociedades ditas tradicionais. A teoria da modernização, que sustenta que as nossas sociedades se pautam pela inovação tecnológica e pelo método científico, emerge como a justificação do declínio relativo dos seniores nas nossas sociedades e da criação de um estatuto social de dependência na idade avançada.

A covariação entre as mudanças de estatutos e papéis e a mudança social conduz tal teoria a postular que o estatuto social das pessoas idosas varia em função do grau de industrialização e desenvolvimento tecnológico da sociedade. O saber válido passou a ser o da ciência e da tecnologia e não o da tradição. A ciência tornou-se hoje "uma esfera plenamente institucionalizada, algo de adquirido nas sociedades contemporâneas, elemento central das referências cognitivas estabelecidas e parte importante dos sistemas de poderes instalados" (Costa e outros, 2005: 9). Através do duplo processo de diferenciação social e de interligação da ciência com a sociedade, ou seja, com as outras instituições e com a vida quotidiana, ela encontra-se, a par das tecnologias, na base da constituição estrutural da sociedade contemporânea e dos modos de existência social que nela se desenvolvem (id., ibid.).

1 O projeto Inclusão e Participação Digital. Comparação de Trajetórias de Uso de Meios Digitais por Diferentes Grupos Sociais em Portugal e nos Estados Unidos decorre do programa UTAustin | Portugal, através de uma parceria entre as Universidades de Austin, Nova de Lisboa e do Porto (ref. ${ }^{\text {a }}$ UTAustin I Portugal/CD/016/2008). 
A perceção de que é significativo o desfasamento entre a amplitude da presença do conhecimento científico nas nossas sociedades e a "fragilidade dos recursos cognitivos e das possibilidades de protagonismo esclarecido da maioria dos cidadãos neste domínio" (id., ibid.: 9-10), em particular dos seniores, permite-nos compreender que existam meios sociais menos predispostos ao acolhimento de uma cultura científica e tecnológica.

Com efeito, a teoria da modernização alimentou, pelo menos até aos anos 80 do século passado, os discursos negativos da velhice, que sublinhavam principalmente a iliteracia científica e tecnológica dos idosos nas sociedades contemporâneas, a par das situações de pobreza, isolamento social, solidão, doença e dependência em que muitos se encontram (Mauritti, 2004: 340).

Contudo, as associações e movimentos políticos de defesa e promoção dos direitos da pessoa idosa passaram a veicular um novo entendimento de velhice. Esta passou a estar "associada de forma apelativa a designações positivas que a projetam num tempo de lazer, de liberdade e de autoaperfeiçoamento" - são exemplo disso expressões como "universidade da terceira idade" e "turismo sénior". Este discurso dirige-se à chamada "terceira idade", que se espera vir a estar integrada na dita sociedade em rede.

O conceito de envelhecimento ativo (ONU, 1982) assume particular relevância no contexto da sociedade em rede. Este conceito foi reforçado na II Assembleia Mundial sobre o Envelhecimento, promovida pela Organização das Nações Unidas (ONU) em Madrid em 2002, e associa precisamente o envelhecimento à atividade económica, social e cultural, a qual se prolonga para além da reforma. Preconiza a aprendizagem ao longo da vida e a introdução de um sistema de reforma mais gradual. Em suma, refere-se ao desenvolvimento de atividades que permitam otimizar as capacidades individuais e manter um bom estado de saúde da pessoa idosa. ${ }^{2}$ Esta definição enfatiza principalmente a participação social, a saúde e o bem-estar dos seniores, sendo utilizada principalmente pela Organização Mundial de Saúde (OMS) (Gonçalves e Dias, 2008).

De acordo com Pestana (2003), trata-se de uma noção que tem sido normalmente associada à atividade (não económica) nos tempos da velhice. Todavia, na perspetiva da política de emprego, refere-se ao conjunto de esforços que visam prolongar no tempo a participação económica dos indivíduos, isto é, que pretendem adiar a sua passagem para a inatividade ou o fim das suas vidas profissionais. Trata-se de uma definição mais ancorada na participação dos trabalhadores mais velhos (55 aos 64 anos) no mercado de emprego, no prolongamento da sua vida laboral e nas condições de trabalho. É de raiz mais laboral e financeira, sendo mais utilizada pela União Europeia (Gonçalves e Dias, 2008).

Embora não se excluam, estas definições ilustram que o próprio conceito de envelhecimento ativo se encontra em discussão: com a sua promoção pretende-se, por exemplo, levar os trabalhadores a manterem-se ativos para além da idade legal

2 Consultar "Resposta da Europa ao envelhecimento da população mundial: promover o progresso económico e social num mundo em envelhecimento". Contribuição da Comissão Europeia para a II Assembleia Mundial sobre o Envelhecimento, Bruxelas, 2002, p. 6. 
da reforma ou procura-se apenas que não se reformem antecipadamente? Em ambos os casos as respostas não são lineares. No espaço comunitário, a idade padrão é de 65 anos, ainda que nos diversos Estados-membros se observem diferentes possibilidades de antecipação. Entre estas encontram-se, por exemplo, a permanência prolongada no desemprego (Guillemard, 2004). Todavia, existem outros processos responsáveis pela retirada precoce dos trabalhadores mais velhos do mercado de trabalho, como é o caso da reconversão tecnológica e organizacional das empresas, da terciarização da economia, da quebra da indústria, da intensificação dos processos de deslocalização empresarial no quadro da globalização, da rejeição de mão de obra com qualificações e competências consideradas, pelas entidades empregadoras, como inadequadas às novas culturas organizacionais (Gonçalves e Dias, 2008).

Apesar de a idade de transição para a reforma ter sido instituída aos 65 anos para praticamente a generalidade dos trabalhadores dos países da União Europeia, este critério demográfico-administrativo é, nos nossos dias, alvo de uma profunda discussão à luz do atual contexto de crise económica e financeira, que coloca em causa a própria sustentabilidade do sistema europeu de pensões.

Independentemente da influência dos discursos mais otimistas acerca do envelhecimento, na verdade, na génese do envelhecimento ativo também estão fatores associados à sustentabilidade dos sistemas financeiros das pensões públicas de reforma, comprometida pelo aumento crescente do peso relativo dos idosos no conjunto da população (Mendes, 2005).

No entanto, podemos concluir que através do conceito de envelhecimento ativo se procura promover a integração social e laboral dos idosos, implementar medidas específicas que promovam alterações nas regras e práticas da organização do trabalho e atenuem os processos de discriminação dos mais velhos, medidas que facilitem, de igual modo, o acesso dos seniores, nomeadamente dos segmentos mais vulneráveis, às atividades culturais e recreativas e fomentem as solidariedades intergeracionais, tanto na família como nos diversos contextos sociais (Gonçalves e Dias, 2008).

As medidas de envelhecimento ativo são compostas por um conjunto de programas que exigem dos idosos um papel pró-ativo, designadamente programas de saúde e bem-estar físico, de ingressos económicos e programas educacionais, formais e informais (Martin e outros, 2007a: 161).

Os primeiros programas visam a promoção de estilos de vida saudáveis, através da adoção de comportamentos adequados por parte dos idosos (e.g., alimentação, exercício, consumo de certas substâncias). Os segundos tentam equilibrar o diferencial da distribuição de benefícios e podem ser de dois tipos: indiretos (consistem na redução de parte ou da totalidade do custo de um serviço ou bem pelo facto de ser para uma pessoa idosa), ou diretos (residem na atribuição de um fundo pecuniário ao idoso, geralmente através da reforma). Por último, os programas educacionais, formais e informais, estão associados ao conceito de "aprendizagem ao longo da vida" e visam o desenvolvimento pessoal da pessoa idosa (e.g., academias seniores, escolas comunitárias, centros para idosos) (id., ibid.: 161-169). Tais programas têm como finalidade fomentar a participação dos idosos; ampliar os 
conteúdos programáticos ministrados e assegurar a sua qualidade. No nosso país, os centros de dia, ora apoiados pelo poder autárquico, ora sustentados pelas instituições de solidariedade social, mas sobretudo pelo setor privado, promovem, geralmente, formação que contempla temáticas como nutrição, informática, saúde, trabalhos manuais, entre outras. $\mathrm{O}$ ensino-aprendizagem das tecnologias digitais conhece, nos nossos dias, uma certa adesão por parte dos seniores conscientes da sua iliteracia neste domínio.

Em suma, existe algum consenso acerca de que o conceito de envelhecimento ativo se refere ao processo de otimização do potencial de bem-estar social, físico e mental das pessoas ao longo da vida, para que este período, que é cada vez mais longo, seja vivido de forma autónoma e ativa (Tamer e Petriz, 2007: 183).

Mais recentemente assiste-se ao desenvolvimento do conceito de envelhecimento produtivo. Este tem por referência um paradigma que procura conceptualizar o envelhecimento a partir de uma perspetiva positiva. Esta perspetiva engloba simultaneamente duas facetas do processo, nomeadamente o impacto do contributo direto decorrente das atividades realizadas pela pessoa idosa nos indivíduos, famílias, grupos ou instituições; e os benefícios que tais atividades podem ter na qualidade de vida dos idosos.

Trata-se de um conceito que articula ao mesmo tempo uma visão instrumental, utilitária ou externa, com uma visão interna ou afetiva com consequências no bem-estar geral deste grupo social (Martin e outros, 2007a: 170). É um conceito que envolve diferentes noções, designadamente o de produção de serviços e o de satisfação de necessidades. Por esta razão, a sua definição ainda não é muito clara, o que conduz a que possa ser confundível com o conceito de envelhecimento ativo (Martin e outros, 2007b: 204).

De qualquer modo, é um conceito que sugere que um sénior produtivo é todo aquele que se envolve em atividades de realização significativas, pessoalmente satisfatórias e com um impacto positivo na sua própria vida e na dos outros (Kaye, Butter e Webster, 2003: 204). Um papel produtivo será todo aquele que produz bens ou serviços, remunerados (e.g., emprego) ou não (e.g., voluntariado). O voluntariado e os programas intergeracionais e de emprego sénior são medidas que se enquadram no âmbito deste conceito (id., ibid.). Mas na verdade não existem atualmente em Portugal projetos devidamente estruturados com esta finalidade.

Independentemente das dificuldades que ambos os conceitos podem suscitar em termos analíticos, é certo que representam vias importantes, quer para a própria investigação, quer para a construção de uma "sociedade para todas as idades" (Tamer e Petriz, 2007: 183).

\section{Envelhecimento e uso de tecnologias digitais}

Como afirmámos antes, "ativo" não se refere unicamente à capacidade de estar fisicamente atuante, mas também ao envolvimento contínuo dos idosos nas questões sociais, económicas, tecnológicas, espirituais, culturais e cívicas (Vallespir e Morey, 2007: 241). Trata-se de um conceito que ultrapassa a abordagem centrada nas 
necessidades, para se focar nos direitos dos seniores em todos os domínios. Neste sentido, abrange, de igual modo, o conceito de educação permanente, também designado educação ao longo da vida, enquanto oportunidade que garante aos indivíduos um conjunto de meios que lhes permite alcançar o equilíbrio entre trabalho, aprendizagem e vida ativa (id. ibid.: 245).

Embora seja fundamental noutras fases do ciclo da vida humana, a educação permanente é muito importante na idade adulta, na medida em que se trata de uma população que necessita de uma maior reconversão e adaptação às mudanças tecnológicas, tal como na terceira e quarta idade. Este conceito refere-se assim a todos os sujeitos de qualquer idade, a todos os níveis educativos, à totalidade dos métodos, meios e agentes de educação (id. ibid.: 241).

Todavia, nas nossas sociedades já não é suficiente a alfabetização tradicional - ler e escrever. Novas formas de ensino-aprendizagem emergem como objetivos da educação permanente. É o caso da linguagem informática e da técnico-científica, em geral.

A grande quantidade de informação gerada pela sociedade em rede permite aos indivíduos novas oportunidades, ao mesmo tempo que exige deles competências operatórias e de descodificação para o seu uso adequado. Neste sentido, a literacia enquanto capacidade de processamento, na vida diária (social, profissional e pessoal), de informação escrita de uso corrente contida em materiais impressos vários (textos, documentos, gráficos), define-se por duas características nucleares: por permitir a análise da capacidade efetiva de utilização na vida quotidiana das competências de leitura, escrita e cálculo; e por remeter para um contínuo de competências que se traduzem em níveis de literacia com graus de dificuldade distintos (Costa e outros, 2000: 1).

Com efeito, é no contexto de uma sociedade em rede que se desenvolve a vida quotidiana de milhões de pessoas, pelo que formar para uma utilização adequada das referidas tecnologias exige novas abordagens pedagógicas. A difusão permanente de informação, genérica e especializada, gerada pelos meios de comunicação em rede, corrobora, à luz do conceito de literacia, a necessidade de "ensinar a aprender", já que "a maior parte da informação se encontra online" (Castells, 2004: 300). Enquanto processo de assimilação de conhecimentos estruturados com determinada finalidade, a literacia (digital) surge como possibilidade de exercício de cidadania (Lima, Nogueira e Burgos, 2008), sendo igualmente fundamental para a construção de identidade, para o sentido que temos do mundo e da capacidade de agirmos nele e com ele (Henriques, 2011).

Enquanto organização social, a sociedade em rede, resultou da interação entre a revolução tecnológica baseada nas tecnologias da informação e da comunicação e na engenharia genética, e os processos sociais, económicos, culturais e políticos do último quarto do século XX. Tem uma existência global, integra as novas tecnologias da informação e da comunicação, como a internet, adaptando-as às suas necessidades, aos seus interesses, valores e projetos (Castells em Cardoso e outros, 2005: 1).

As redes de comunicação da internet, estando na base da constituição da própria sociedade em rede, permitiram aos seus utilizadores situarem-se num novo contexto; perceberem a necessidade de se autoinformarem e de se autoeducarem 
num mundo de crescente valorização da formação ao longo da vida e da inovação. Permitiram, igualmente, estabelecer redes de comunicação horizontal independentes dos meios de comunicação de massa e construir a autonomia da sociedade civil global como contrapeso à crise de legitimidade das instituições políticas (id., ibid.).

Mas a centralidade da sociedade em rede também tem vindo a acentuar várias desigualdades entre países, grupos e pessoas no que diz respeito ao acesso à internet (Henriques, 2011:3). A infoexclusão designa tal desigualdade e refere-se ao acesso limitado ou inexistente à rede, ou à incapacidade de os sujeitos tirarem partido dela (Castells, 2004: 287). No caso dos idosos ser excluído digitalmente significa, simultaneamente, não ter acesso e não poder executar um conjunto de ações essenciais para as suas necessidades básicas diárias.

O conceito de inclusão digital emerge assim como uma forma de atenuar as diferenças entre aqueles que dominam as tecnologias da informação e da comunicação e os que não o fazem, tal como sucede com uma parte significativa dos seniores em Portugal. Incluir, tecnologicamente, significa apreender o discurso da tecnologia, não apenas na ótica de execução e de qualificação, mas também na perspetiva de os sujeitos serem capazes de influir sobre a importância e finalidades da própria tecnologia digital.

Tal definição tem subjacente a noção de literacia digital enquanto processo de assimilação de conhecimentos estruturados com determinada finalidade, mas também como possibilidade de construção de cidadania (Lima, Nogueira e Burgos, 2008). Em suma, a literacia vai além das capacidades, por parte dos indivíduos, de compreensão e uso da informação escrita impressa em materiais diversos, para se traduzir, de igual modo, num conjunto de competências que aqueles mobilizam na sua vida quotidiana numa sociedade em rede.

A formação dos seniores, neste âmbito, emerge assim como um meio de alcançarem uma maior autonomia, participação social, conhecimentos, desenvolvimento pessoal, a par de aptidões concretas que possibilitem o seu relacionamento com outros indivíduos (Vallespir e Morey, 2007: 241). Permite-lhes ainda desfrutar do tempo de forma diferente após a saída do mundo profissional ativo.

Apesar de em Portugal, em 2010, se assistir a um aumento dos agregados domésticos que dispõem de acesso a computador (60\%) e a internet (54\%) em casa, a sua utilização ainda é diferente consoante os escalões etários (INE, 2010).

Dados relativos à utilização do computador e da internet por grupo etário revelam que o grupo dos mais velhos (65-74 anos) é o que utiliza menos as referidas tecnologias, embora se observe uma tendência crescente para o seu uso em 2010 e 2011 (ver quadro 1).

Mas ainda se observa uma grande discrepância ao nível da utilização e acesso a computadores e à internet entre os diferentes grupos etários em Portugal. Este acesso é superior entre os mais jovens (16-24 anos e 25-34 anos), o que evidencia uma maior literacia destas gerações nas novas tecnologias da informação e da comunicação. A utilização destas tecnologias varia assim na razão inversa da idade, sendo os mais jovens que mais contribuem para a evolução positiva destes indicadores no nosso país. Contrariamente, o uso do telemóvel conhece uma certa 
Quadro 1 Utilização do computador e da internet em \% do total de indivíduos por grupo etário

\begin{tabular}{l|c|c|c|c|c|c}
\hline \multirow{2}{*}{ Grupo etário } & \multicolumn{3}{|c|}{ Computador } & \multicolumn{3}{c}{ Internet } \\
\cline { 2 - 7 } & $2009 \%$ & $2010 \%$ & $2011 \%$ & $2009 \%$ & $2010 \%$ & $2011 \%$ \\
\hline Total & 51,4 & 55,4 & 58,2 & 46,5 & 51,1 & 55,3 \\
16-24 anos & 92,2 & 94,0 & 95,0 & 88,1 & 89,3 & 92,7 \\
25-34 anos & 82,4 & 82,1 & 85,2 & 77,1 & 79,2 & 82,1 \\
35-44 anos & 59,6 & 66,9 & 72,9 & 53,3 & 62,4 & 70,5 \\
$45-54$ anos & 41,3 & 46,7 & 50,5 & 36,0 & 40,6 & 45,7 \\
55-64 anos & 26,9 & 32,0 & 31,3 & 21,4 & 27,7 & 28,3 \\
65-74 anos & 8,1 & 12,7 & 13,9 & 6,6 & 10,4 & 12,5 \\
\hline
\end{tabular}

Fonte: INE, Inquérito à Utilização de Tecnologias da Informação e da Comunicação nas Famílias (a partir de 2003); Pordata

transversalidade nos diferentes escalões etários. Apesar de serem os mais jovens a usar maioritariamente esta tecnologia, entre os seniores (55-74 anos), em 2008, $64,7 \%$ eram utilizadores, e em 2010 este valor alcançou os 76,5\% (INE, 2010). O telemóvel é uma das tecnologias mais generalizadas em Portugal, à qual os próprios idosos também aderiram.

Assim, a menor adesão às tecnologias da informação e da comunicação como o computador e a internet, entre os mais velhos, pode-se explicar, por um lado, pela iliteracia no que diz respeito ao seu uso e manipulação, mas também pelo custo dos equipamentos e serviços a elas associados (e.g., programas, serviços de eletricidade, assistência, etc.).

Com efeito, esta é uma população que tem que aprender a ler a nova linguagem gerada pelas tecnologias da informação e da comunicação e a incorporá-la nas suas práticas sociais. Mas a predisposição para a aprendizagem não é indiferente às condições biológicas, sociais e psicológicas em que cada idoso se encontra (e.g., mobilidade/flexibilidade, capacidades cognitivas e sensoriais, de memória e atenção, etc.). Tais condições exigem um contexto formativo que acione métodos específicos de ensino-aprendizagem das novas tecnologias, permitindo, por seu intermédio, explorar outras possibilidades de desenvolvimento individual e atender ao conjunto de expectativas e necessidades que a população mais velha tem acerca do uso das tecnologias da informação e da comunicação na sua vida quotidiana. Porém, o facto de os mais velhos apresentarem dificuldades não inviabiliza o seu processo formativo, ou seja, não é condição de exclusão digital.

Uma das expectativas dos seniores, neste âmbito, está associada à sua participação nas redes de comunicação e, por essa via, à criação de novas sociabilidades. Através de cursos de informática, as pessoas idosas obtêm formação que lhes permite aceder a redes de comunicação e encetar novas relações sociais. Muitos dos conteúdos destes cursos estão voltados para o entretenimento e o lazer. Os chats, os grupos de discussão, bem como o próprio e-mail são elementos que permitem a comunicação com familiares e amigos. Os passeios virtuais em centros comerciais, livrarias, museus são outra atividade muito procurada pelos mais velhos (Doll, Pasqualotti e Barone, 2007). 
O contacto com o computador proporciona aos idosos o acesso a novas relações, mas também abre novas possibilidades de inserção na família, fomentando as interações entre gerações, através, por exemplo, de atividades lúdicas, como é o caso dos jogos interativos, ou da comunicação por e-mail e outros serviços. Por outras palavras, surge como um meio que promove as relações intergeracionais.

Os recursos do computador e da internet enquadram-se nos conceitos antes apresentados de educação permanente, literacia digital e envelhecimento produtivo, na medida em que, ao proporcionarem à população mais velha atividades de realização significativas, permitem-lhes uma adaptação às mudanças tecnológicas e, por esta via, maiores hipóteses de desenvolvimento pessoal, autonomia e integração nas sociedades atuais.

Porém, a apropriação do computador pelos idosos implica três aspetos articulados entre si: o operacional (o idoso aprende a operar com o computador, desenvolvendo a habilidade e destreza necessárias, bem como competências ao nível dos recursos de hardware e software); a linguagem da máquina (envolve a leitura, interpretação e compreensão da nova linguagem tecnológica da comunicação); a abordagem pedagógica. Esta é, como referimos antes, fundamental para a interação/comunicação e para a construção do conhecimento por parte dos idosos (Doll, Pasqualotti e Barone, 2007).

De qualquer modo, o uso do computador e da internet surge quer como uma ferramenta colaborativa, permitindo a criação de espaços de comunicação e interação, quer como uma forma de o idoso resolver uma situação-problema (e.g., saúde, acesso a serviços, etc.).

Por último, o conceito de género, entendido como a elaboração cultural do sexo (Guionnet e Neveu, 2005: 5), proporcionou-nos uma lente de leitura importante para a compreensão dos diferentes processos de interação dos homens e mulheres mais velhos com as tecnologias da informação e da comunicação. Ao termos em consideração o referido conceito, passamos a estar, de igual modo, atentos, aos processos que levam à interiorização pelos homens e mulheres (mais velhos) dos efeitos das atribuições sociais aos comportamentos que se esperam e exprimem no domínio das novas tecnologias da informação e da comunicação.

\section{Abordagem metodológica}

Com a finalidade de estudar a relação dos seniores mais jovens e dos mais velhos com as tecnologias da informação e da comunicação, em particular com o computador e a internet, bem como as principais motivações e necessidades que estão subjacentes ao seu uso, o estudo articula uma análise qualitativa e extensiva. No primeiro caso, foram analisadas 30 entrevistas semiestruturadas das 130 realizadas a famílias residentes em Portugal entre os meses de novembro e dezembro de 2009, no âmbito do projeto Inclusão e Participação Digital (2009-2011). Foram selecionadas as entrevistas realizadas aos indivíduos com idades compreendidas entre os 55 e os 90 anos. Embora se trate de uma faixa etária muito extensa, os seniores foram subdivididos entre os mais jovens (55-65 anos) e os mais velhos (66 ou mais anos). 
Procedeu-se a uma análise de conteúdo temática principalmente da segunda parte do guião de entrevista, composta pelos seguintes núcleos: (1) história pessoal com os média; (2) usos atuais dos média; (3) uso do computador e da internet. O ponto de vista subjetivo dos seniores é apresentado sob a forma de transcrições dos seus discursos.

De seguida, foi administrado um inquérito por questionário a uma amostra composta por 792 utilizadores de espaços de internet (bibliotecas públicas, juntas de freguesia, etc.) e frequentadores de centros de emprego das cidades de Lisboa, Porto e Coimbra. Pretendia-se o conhecimento quantitativo acerca da utilização da internet e de outras tecnologias digitais. Apesar de esta metodologia permitir, a partir de um conjunto de respostas individuais, a generalização dos resultados a conjuntos mais amplos da população (Ghiglione e Matalon, 2001), no nosso estudo tal não é possível, em virtude de termos utilizado uma subamostra composta por 91 seniores ( 54 com idades entre os 55 e os 65 anos e 37 com 66 ou mais anos), os únicos existentes na amostra principal.

O inquérito administrado à amostra citada é composto principalmente por questões fechadas e semifechadas/semiabertas (mistas). Integra 27 questões dirigidas a utilizadores e a não utilizadores da internet e de outras tecnologias da informação e da comunicação. Termina com um conjunto de questões de caracterização sociodemográfica.

Sem deixar de ter em conta a interação entre os conceitos de referência evocados e a informação empírica recolhida através das entrevistas e dos inquéritos, avançámos para a construção de um modelo analítico rico em descrições e proposições de interpretação de processos sociais de uso e de interesse pelas tecnologias digitais por parte dos seniores. Não se pretendendo uma análise meramente descritiva, o trabalho de análise empírica dos dados foi sempre acompanhado de um objetivo de teorização (Flick, 2005).

\section{Caracterização da população}

Como foi referido, a nossa amostra foi subdividida em dois grupos etários: os seniores mais jovens (55-65 anos) e os mais velhos (66 ou mais anos). Embora, à luz de outros critérios classificatórios de velhice, os seniores com mais de 65 anos ainda sejam designados "jovens-velhos" (Riley, 1988), optámos por esta classificação, em virtude de não termos na nossa população um número suficiente de indivíduos classificados como "velhos-velhos", isto é, com mais de 75 anos (id., ibid.).

Assim, fazem parte do nosso universo de análise $(\mathrm{N}=91)$ um número aproximado de homens e mulheres, com um ligeiro predomínio dos seniores mais jovens (ver quadro 2).

Na nossa amostra, predominam baixos níveis de escolaridade, sobretudo entre os seniores mais velhos. Apesar de, entre os seniores mais jovens, se observar a mesma tendência, constata-se uma maior presença de indivíduos, de ambos os sexos, com o ensino superior $(21,1 \%)$ (ver quadro 3$)$. 
Quadro 2 Género e escalão etário dos inquiridos

\begin{tabular}{l|c|c|c|c|c|c}
\hline \multirow{2}{*}{ Género } & \multicolumn{4}{|c|}{ Escalão etário } & \multicolumn{2}{c}{ Total } \\
\cline { 2 - 6 } & \multicolumn{2}{|c|}{$55-65$ anos } & \multicolumn{2}{c}{66 ou mais anos } & N & $\%$ \\
\cline { 2 - 6 } & $\mathrm{N}$ & $\%$ & 17 & 50,0 & 49 & 53,8 \\
Masculino & 32 & 56,1 & 17 & 50,0 & 42 & 46,2 \\
Feminino & 25 & 43,9 & 34 & 100,0 & 91 & 100,0 \\
Total & 57 & 100,0 & & & \\
\hline
\end{tabular}

Quadro 3 Nível de instrução dos inquiridos, escalão etário e género

\begin{tabular}{|c|c|c|c|c|c|c|c|}
\hline \multirow{3}{*}{$\begin{array}{l}\text { Escalão } \\
\text { etário }\end{array}$} & \multirow{3}{*}{$\begin{array}{l}\text { Nível de instrução } \\
\text { dos inquiridos }\end{array}$} & \multicolumn{4}{|c|}{ Género } & \multirow{2}{*}{\multicolumn{2}{|c|}{ Total }} \\
\hline & & \multicolumn{2}{|c|}{ Masculino } & \multicolumn{2}{|c|}{ Feminino } & & \\
\hline & & $\mathrm{N}$ & $\%$ & $\mathrm{~N}$ & $\%$ & $\mathrm{~N}$ & $\%$ \\
\hline $55-65$ anos & $\begin{array}{l}1 .^{\circ} \text { ciclo } \\
2 .^{\circ} \text { ciclo } \\
3 .^{\circ} \text { ciclo } \\
\text { Ensino secundário incompleto } \\
\text { Ensino secundário completo } \\
\text { Frequência ensino superior } \\
\text { Ensino superior completo } \\
\text { Total }\end{array}$ & $\begin{array}{r}4 \\
5 \\
3 \\
2 \\
8 \\
3 \\
7 \\
32\end{array}$ & $\begin{array}{r}12,5 \\
15,6 \\
9,4 \\
6,3 \\
25,0 \\
9,4 \\
21,9 \\
100,0\end{array}$ & $\begin{array}{r}6 \\
0 \\
5 \\
3 \\
6 \\
0 \\
5 \\
25\end{array}$ & $\begin{array}{r}24,0 \\
0,0 \\
20,0 \\
12,0 \\
24,0 \\
0,0 \\
20,0 \\
100,0\end{array}$ & $\begin{array}{r}10 \\
5 \\
8 \\
5 \\
14 \\
3 \\
12 \\
57\end{array}$ & $\begin{array}{r}17,5 \\
8,8 \\
14,0 \\
8,8 \\
24,6 \\
5,3 \\
21,1 \\
100,0\end{array}$ \\
\hline $\begin{array}{l}66 \text { ou } \\
\text { mais anos }\end{array}$ & $\begin{array}{l}1 .^{\circ} \text { ciclo } \\
2 .^{\circ} \text { ciclo } \\
3 .^{\circ} \text { ciclo } \\
\text { Ensino secundário incompleto } \\
\text { Ensino secundário completo } \\
\text { Frequência ensino superior } \\
\text { Ensino superior completo } \\
\text { Total }\end{array}$ & $\begin{array}{r}3 \\
0 \\
4 \\
3 \\
1 \\
1 \\
5 \\
17\end{array}$ & $\begin{array}{r}17,6 \\
0,0 \\
23,5 \\
17,6 \\
5,9 \\
5,9 \\
29,4 \\
100,0\end{array}$ & $\begin{array}{r}6 \\
1 \\
4 \\
3 \\
1 \\
0 \\
2 \\
17\end{array}$ & $\begin{array}{r}35,3 \\
5,9 \\
23,5 \\
17,6 \\
5,9 \\
0,0 \\
11,8 \\
100,0\end{array}$ & $\begin{array}{r}9 \\
1 \\
8 \\
6 \\
2 \\
1 \\
7 \\
34\end{array}$ & $\begin{array}{r}26,5 \\
2,9 \\
23,5 \\
17,6 \\
5,9 \\
2,9 \\
20,6 \\
100,0\end{array}$ \\
\hline
\end{tabular}

Relativamente à condição laboral atual dos respondentes, a maioria encontram-se reformados $(53,8 \%)$. Nesta condição estão principalmente os seniores mais velhos $(91,2 \%)$, com destaque para as mulheres (100\% para $82,4 \%$ dos homens).

Entre os seniores mais jovens, $31,6 \%$ encontram-se reformados, sobretudo os homens (40,6\% para 20,0\% das mulheres). Porém, 33,3\% dos que têm entre 55 e 65 anos estão desempregados. Neste escalão etário volta a observar-se uma certa assimetria em termos da condição perante o trabalho, na medida em que o desemprego afeta, na nossa amostra, principalmente as mulheres mais velhas (48,0\% para $21,9 \%$ dos homens). 


\section{Usos diferenciados das tecnologias digitais: motivações e interesses}

O acesso às tecnologias da informação e da comunicação é, como referimos antes, uma forma de promover a inclusão social dos mais velhos, atenuando possíveis focos de discriminação. As tecnologias digitais, em particular o uso do computador e da internet, possibilitam o acesso, sobretudo dos segmentos mais vulneráveis da população idosa, a atividades culturais e recreativas, mas também a um conjunto de serviços e bens. Fomentam, ao mesmo tempo, as solidariedades intergeracionais, tanto na família como nos diversos contextos sociais. Todavia, a nossa amostra revela uma baixa predisposição para o uso da internet.

Apesar da tendência para um reduzido uso da internet entre os respondentes, ele é diferente em função do género e da idade dos seniores. São os idosos mais jovens, homens e mulheres, que revelam uma utilização da internet que oscila entre muito frequente e pouco frequente. Com efeito, $48,2 \%$ afirmam que existem períodos em que usam frequentemente e períodos em que usam pouco a internet, salientando-se nesta categoria os homens (61,3\% para 32,0\% das mulheres). Neste escalão etário, são novamente mais os homens que afirmam usar frequentemente a internet (32,3\% contra $28,0 \%$ das mulheres). Esta tendência é inversa nos escalões mais velhos, principalmente entre as mulheres. Com efeito, $52,9 \%$ das seniores mais velhas nunca usaram a internet. Tal está relacionado com os baixos níveis de formação escolar da população mais velha da nossa amostra, que revela uma maior iliteracia face a esta tecnologia da informação e da comunicação (ver quadro 4).

Todavia, a relação dos seniores com tecnologias como a televisão e o telemóvel é completamente distinta da descrita no caso da internet (ver figura 1).

Com efeito, a televisão está presente em $100 \%$ dos agregados domésticos dos seniores de ambos os escalões etários. Observa-se a mesma tendência no caso do telemóvel, com uma incidência de $100 \%$ entre as seniores jovens e mais velhas. Este equipamento também se encontra fortemente presente nos seniores de ambos escalões do sexo masculino, não havendo, por isso, diferenças significativas de género ou idade.

O telefone fixo está, de igual modo, presente nos agregados domésticos dos seniores, principalmente das mulheres (jovens e mais velhas). Por seu turno, o computador portátil e de secretária são mais frequentes nos agregados domésticos dos seniores mais jovens, de ambos os sexos. Esta tendência observa-se também no caso da televisão por cabo ou satélite (62,5\% de homens e $80,0 \%$ de mulheres).

Aidade, mais do que o género, explica uma certa apetência por equipamentos como o computador, consola e consola ligada à internet, presentes sobretudo nos agregados familiares dos seniores mais jovens de ambos os sexos. Entre os seniores mais velhos observa-se uma menor presença do computador de secretária $(29,4 \%$ dos homens e $47,0 \%$ das mulheres) ou portátil ( $47,1 \%$ e 35,3\%, respetivamente).

À ausência de necessidade pessoal e social de computador, junta-se uma certa iliteracia no que diz respeito ao seu uso, o que é tanto mais acentuado, quanto mais os seniores avançam na idade. Esta situação é corroborada por alguns dos testemunhos dos nossos entrevistados: 
Quadro 4 Frase que melhor descreve o uso da internet por escalão etário e género

\begin{tabular}{|c|c|c|c|c|c|c|c|}
\hline \multirow{3}{*}{ Escalão etário } & \multirow{3}{*}{ Uso da internet } & \multicolumn{4}{|c|}{ Género } & \multirow{2}{*}{\multicolumn{2}{|c|}{ Total }} \\
\hline & & \multicolumn{2}{|c|}{ Masculino } & \multicolumn{2}{|c|}{ Feminino } & & \\
\hline & & $\mathrm{N}$ & $\%$ & $\mathrm{~N}$ & $\%$ & $\mathrm{~N}$ & $\%$ \\
\hline 55-65 anos & $\begin{array}{l}\text { Eu nunca usei a internet } \\
\text { Já fui utilizador da internet mas agora não sou } \\
\text { Existem períodos em que uso frequentemente } \\
\text { e períodos em que uso pouco } \\
\text { Eu uso muito frequentemente a internet } \\
\text { Total }\end{array}$ & $\begin{array}{r}2 \\
0 \\
19 \\
10 \\
31\end{array}$ & $\begin{array}{r}6,5 \\
0,0 \\
61,3 \\
32,3 \\
100,0\end{array}$ & $\begin{array}{l}8 \\
2 \\
8 \\
7 \\
7 \\
25\end{array}$ & $\begin{array}{r}32,0 \\
8,0 \\
32,0 \\
28,0 \\
100,0\end{array}$ & $\begin{array}{r}10 \\
2 \\
27 \\
17 \\
56\end{array}$ & $\begin{array}{r}17,9 \\
3,6 \\
48,2 \\
30,4 \\
100,0\end{array}$ \\
\hline $\begin{array}{l}66 \text { ou mais } \\
\text { anos }\end{array}$ & $\begin{array}{l}\text { Eu nunca usei a internet } \\
\text { Eu nunca quis usar a internet } \\
\text { Existem períodos em que uso frequentemente } \\
\text { e períodos em que uso pouco } \\
\text { Eu uso muito frequentemente a internet } \\
\text { Total }\end{array}$ & $\begin{array}{r}2 \\
1 \\
8 \\
6 \\
17\end{array}$ & $\begin{array}{r}11,8 \\
5,9 \\
47,1 \\
35,3 \\
100,0\end{array}$ & $\begin{array}{r}9 \\
1 \\
5 \\
\\
2 \\
17\end{array}$ & $\begin{array}{r}52,9 \\
5,9 \\
29,4 \\
\\
11,8 \\
100,0\end{array}$ & $\begin{array}{r}11 \\
2 \\
13 \\
\\
8 \\
34\end{array}$ & $\begin{array}{r}32,4 \\
5,9 \\
38,2 \\
\\
23,5 \\
100,0\end{array}$ \\
\hline
\end{tabular}

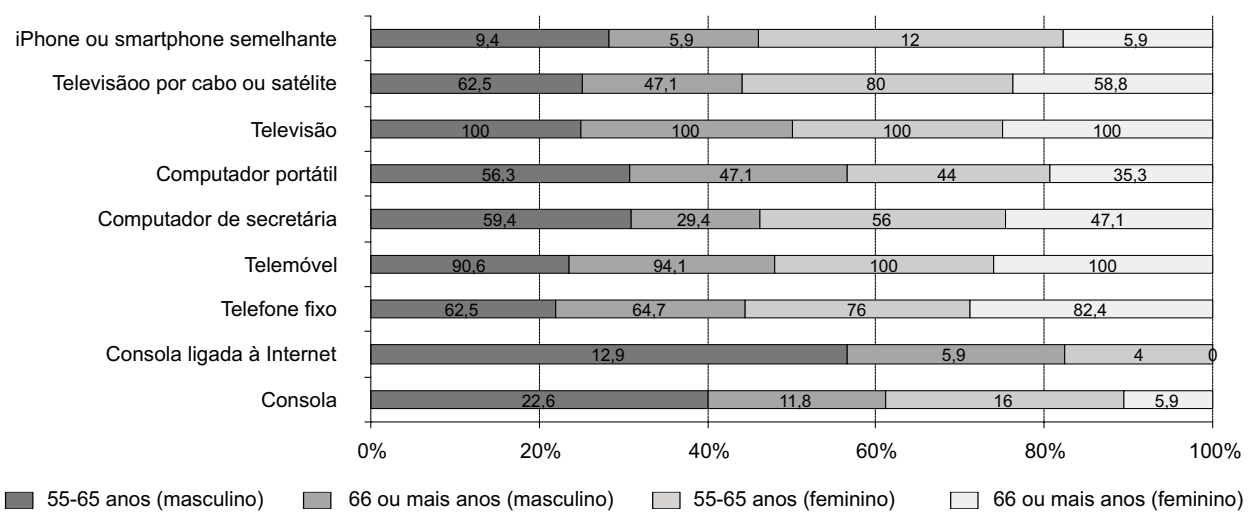

Figura 1 Tipo de equipamento existente no agregado familiar por escalão etário e género

Não, um computador? Eu não sei, alguma vez sei mexer nisso? Eu nem sei ver o que é um computador. [Dália, 78 anos, reformada]

Porém, também existem situações em que, apesar de haver um computador no lar, o sénior não o utiliza, por razões idênticas às supramencionadas. É o caso de Manuel, de 63 anos, para quem o computador é um "meio de comunicação", foi adquirido "para os filhos", mas "nunca usa", embora seja empresário.

A análise das entrevistas permite-nos, de igual modo, conhecer as motivações e interesses dos seniores que na nossa amostra utilizam o computador. Diva é das poucas seniores jovens que usa computador para vários fins: 
Eu uso desde 1998. [...] Eu ouço música, eu vejo filme, eu me informo de tudo o que há no mundo, pesquiso. Dá para fazer trabalho, dependendo do que você quer. Você tem acesso a todos os programas. [56 anos, empregada de limpeza]

Henriqueta começou a usar computador por razões de ordem profissional:

Eu comecei a mexer no computador como instrumento de trabalho. Portanto, há uns 15, 20 anos. Houve um projeto que era o projeto Minerva, era mesmo um dos primeiros de computador... portanto, a minha alfabetização informática começou aí. [...] Eu comecei com os computadores em que era preciso ter quase um curso enorme para vencer o teclado e o problema dos botões na minha geração e mais aquela confusão toda. Não era chegar lá, abrir o programa e escrever. [...] Portanto, eu aprendi a mexer, a utilizar o computador na aula como instrumento de trabalho. A partir daí nunca mais parei. [58 anos, professora]

O mesmo sucedeu com Fernando; todavia, atribui-lhe funções de entretenimento e informativas:

No meu caso, atualmente, serve apenas para me divertir. Eu antes usava para o trabalho, para desenho dos moldes, das maquinações. Como agora isso já não é feito, uso mais para me divertir e, acima de tudo, para me informar. [56 anos, operador de máquinas]

Lurdes, apesar de usar raramente computador, fá-lo com fins de comunicação:

Praticamente não o utilizo. Eu utilizava para falar com a minha filha quando 'tava em África... estive quatro anos lá, em serviço de cooperação em Guiné-Bissau, era professora. [59 anos, reformada]

A baixa predisposição para a utilização de computador, assim como a sua inexistência no lar, principalmente entre os seniores mais velhos está, de certa forma, relacionada com um fraco acesso à internet e seu uso, não obstante os entrevistados terem conhecimento dos locais onde este serviço poderá estar acessível (e.g., bibliotecas públicas).

Mas, entre aqueles que usam a internet, voltamos a constatar diferenças ao nível do seu acesso em função da idade e do género. Para os seniores mais jovens do sexo masculino o acesso faz-se primeiro em casa $(39,9 \%)$, na biblioteca $(39,0 \%)$ e depois no trabalho $(26,8 \%)$. A primeira situação observa-se, de igual modo, entre os seniores mais velhos, apesar de a ordem ser inversa: acesso na biblioteca (52,9\%) e, de seguida, em casa $(47,1 \%)$. O acesso no trabalho não se faz devido à condição maioritária de reformados em que se encontram os nossos respondentes mais velhos. No caso das mulheres, as mais jovens têm primeiramente acesso em casa $(31,7 \%)$ e na biblioteca $(14,6 \%)$, enquanto que para as seniores mais velhas estes dois espaços aparecem em igualdade de circunstâncias $(11,8 \%)$ (ver quadro 5$)$. 
Quadro 5 Locais de acesso à internet por escalão etário e género

\begin{tabular}{|c|c|c|c|c|c|c|c|}
\hline \multirow{3}{*}{ Escalão etário } & \multirow{3}{*}{ Locais de acesso à internet } & \multicolumn{4}{|c|}{ Género } & \multirow{2}{*}{\multicolumn{2}{|c|}{ Total }} \\
\hline & & \multicolumn{2}{|c|}{ Masculino } & \multicolumn{2}{|c|}{ Feminino } & & \\
\hline & & $\mathrm{N}$ & $\%$ & $\mathrm{~N}$ & $\%$ & $\mathrm{~N}$ & $\%$ \\
\hline $55-65$ anos & $\begin{array}{l}\text { Acesso em casa } \\
\text { Acesso no trabalho } \\
\text { Acesso na escola ou universidade } \\
\text { Acesso num cibercafé } \\
\text { Acesso em casa de um amigo ou familiar } \\
\text { Acesso à internet no telemóvel } \\
\text { Acesso à internet na biblioteca } \\
\text { Noutros locais } \\
\text { Total }\end{array}$ & $\begin{array}{r}16 \\
11 \\
2 \\
4 \\
3 \\
1 \\
16 \\
3 \\
26\end{array}$ & $\begin{array}{r}39,0 \\
26,8 \\
4,9 \\
9,8 \\
7,3 \\
2,4 \\
39,0 \\
7,3 \\
63,4\end{array}$ & $\begin{array}{r}13 \\
4 \\
0 \\
1 \\
0 \\
0 \\
6 \\
0 \\
15\end{array}$ & $\begin{array}{r}31,7 \\
9,8 \\
0,0 \\
2,4 \\
0,0 \\
0,0 \\
14,6 \\
0,0 \\
36,6\end{array}$ & $\begin{array}{r}29 \\
15 \\
2 \\
5 \\
3 \\
1 \\
22 \\
3 \\
41\end{array}$ & $\begin{array}{r}70,7 \\
36,6 \\
4,9 \\
12,2 \\
7,3 \\
2,4 \\
53,7 \\
7,3 \\
100,0\end{array}$ \\
\hline $\begin{array}{l}66 \text { ou mais } \\
\text { anos }\end{array}$ & $\begin{array}{l}\text { Acesso em casa } \\
\text { Acesso no trabalho } \\
\text { Acesso num cibercafé } \\
\text { Acesso em casa de um amigo ou familiar } \\
\text { Acesso à internet no telemóvel } \\
\text { Acesso à internet na biblioteca } \\
\text { Total }\end{array}$ & $\begin{array}{r}8 \\
2 \\
4 \\
0 \\
1 \\
9 \\
13\end{array}$ & $\begin{array}{r}47,1 \\
11,8 \\
23,5 \\
0,0 \\
5,9 \\
52,9 \\
76,5\end{array}$ & $\begin{array}{l}2 \\
0 \\
0 \\
1 \\
0 \\
2 \\
4\end{array}$ & $\begin{array}{r}11,8 \\
0,0 \\
0,0 \\
5,9 \\
0,0 \\
11,8 \\
23,5\end{array}$ & $\begin{array}{r}10 \\
2 \\
4 \\
1 \\
1 \\
11 \\
17\end{array}$ & $\begin{array}{r}58,8 \\
11,8 \\
23,5 \\
5,9 \\
5,9 \\
64,7 \\
100,0\end{array}$ \\
\hline
\end{tabular}

Nota: Questão de escolha múltipla, pelo que as percentagens são calculadas por referência ao total de indivíduos que escolheram uma ou mais possibilidades de resposta.

Em suma, observa-se, na nossa amostra, uma fraca predisposição para o uso das tecnologias da informação e da comunicação, principalmente entre as mulheres mais velhas.

Porém, os seniores que usam a internet fazem-no com motivações e interesses distintos. É o caso das seniores mais jovens que usam internet para vários fins, destacando-se aqui aquelas que têm o ensino superior. Esta é a situação de Sílvia Elisa, por exemplo, que usa a internet com finalidades distintas e sobretudo no local de trabalho:

[...] Pelo menos uma vez por dia, para ver o meu e-mail, para procurar alguma informação... [63 anos, professora]

Embora possua o 2.ำ ciclo incompleto, Diva também não abdica da sua utilização diária para fins de comunicação e de entretenimento:

Eu uso [internet] para falar com meus amigos no mundo todo. Falo com meus familiares. Me comunico por e-mail, baixo música, oiço música, vejo filme, tanta coisa! [56 anos, empregada de limpeza]

José usa, de igual modo, a internet assiduamente e para vários fins:

Uso o dia todo. [...] Tudo relacionado com trabalho, envio de e-mail e recebimento e essas coisas assim, não há outra utilidade que não seja isso. [58 anos, comerciante] 
O mesmo sucede com Fernando:

Para divertimento e busca de informação, porque há situações na internet que não conseguimos ter na televisão, por exemplo. Ao menos, não no momento, não de imediato. Não quer dizer que não venha ter, mas naquele momento, portanto, eu tenho acesso, a tudo na internet; na televisão já não; nem na rádio. Aliás, sempre fui fascinado pela rádio. Mas não é como a internet. [56 anos, operador de máquinas]

Os seniores mais velhos que usam a internet revelam igualmente que o fazem com vários fins. Tal sucede com Joaquim, que adquiriu o computador após a reforma e elege a internet, depois do telemóvel, como o principal meio de comunicação:

É mais o telemóvel, depois é a net, o gmail. Gasto mais tempo na net a ouvir música, ler e ver... uso o YouTube para certas coisas. [68 anos, reformado]

Lúcio consulta a internet "todos os dias à noite". Afirma:

Vou à internet ver o Google, navego ali para ver as coisas que mais me interessam [...] vou pela eletrónica porque eu sempre fui maluco pela eletrónica. [69 anos, reformado]

Arlindo também mantém uma relação próxima com o computador e a internet, sobretudo para procurar informação e entretenimento:

Consulto... quando tenho uma dúvida, já não vou à enciclopédia, vou à net em termos de informação do dia a dia, depois informação de conhecimento. Uma dor qualquer, busca aí, tau, às duas por três saímos de lá com 50 doenças. Depois também me divirto na parte dos filmes e da fotografia, meto-me um bocado a fazer coisas, até faço um género de animação com eles (netos), principalmente quando é os jogos dos pais com os filhos, do hóquei, eu gozo com eles. [70 anos, reformado]

Os dados apresentados evidenciam, de alguma forma, uma relação entre género, idade dos entrevistados e uso da internet. São, com efeito, os homens seniores (inclusive os mais velhos) que revelam um uso mais frequente desta tecnologia. No caso das mulheres, são as idosas mais jovens que o fazem, embora por razões distintas. Apesar de alguns seniores mais jovens usarem a internet por razões profissionais, os mais velhos fazem-no por necessidades de pesquisa, obtenção de informação, comunicação, entretenimento, lazer e interação com as gerações mais novas (filhos e netos). Nas mulheres idosas mais jovens destaca-se o uso com fins profissionais, mas também de comunicação e interação com familiares e amigos. Estas razões são comuns ao uso do computador.

Os dados evidenciam, igualmente, uma relação entre o uso da internet e o incremento dos contactos com familiares ou outras pessoas, com destaque para os seniores mais velhos do sexo masculino. Entre estes observa-se uma tendência para o aumento dos contactos, quer com familiares (que vivem próximo ou longe), quer com pessoas com quem partilham interesses pessoais e passatempos. Nos seniores 
Quadro 6 Uso da internet e aumento/manutenção dos contactos por escalão etário e género

\begin{tabular}{|c|c|c|c|c|c|c|c|c|}
\hline \multirow{3}{*}{ Contactos } & \multirow{3}{*}{$\begin{array}{l}\text { Escalão } \\
\text { etário }\end{array}$} & \multirow{3}{*}{$\begin{array}{l}\text { Aumento/ } \\
\text { manutenção }\end{array}$} & \multicolumn{4}{|c|}{ Género } & \multirow{2}{*}{\multicolumn{2}{|c|}{ Total }} \\
\hline & & & \multicolumn{2}{|c|}{ Masculino } & \multicolumn{2}{|c|}{ Feminino } & & \\
\hline & & & $\mathrm{N}$ & $\%$ & $\mathrm{~N}$ & $\%$ & $\mathrm{~N}$ & $\%$ \\
\hline \multirow{2}{*}{$\begin{array}{l}\text { Amigos e família } \\
\text { que vivem longe }\end{array}$} & $55-65$ anos & $\begin{array}{l}\text { Aumentou } \\
\text { Manteve } \\
\text { Não sabe/não responde } \\
\text { Total }\end{array}$ & $\begin{array}{r}6 \\
20 \\
1 \\
27\end{array}$ & $\begin{array}{r}22,2 \\
74,1 \\
3,7 \\
100,0\end{array}$ & $\begin{array}{r}5 \\
10 \\
0 \\
15\end{array}$ & $\begin{array}{r}33,3 \\
66,7 \\
0,0 \\
100,0\end{array}$ & $\begin{array}{r}11 \\
30 \\
1 \\
42\end{array}$ & $\begin{array}{r}26,2 \\
71,4 \\
2,4 \\
100,0\end{array}$ \\
\hline & $\begin{array}{l}66 \text { ou } \\
\text { mais anos }\end{array}$ & $\begin{array}{l}\text { Aumentou } \\
\text { Manteve } \\
\text { Total }\end{array}$ & $\begin{array}{r}8 \\
6 \\
14\end{array}$ & $\begin{array}{r}57,1 \\
42,9 \\
100,0\end{array}$ & $\begin{array}{l}1 \\
4 \\
5\end{array}$ & $\begin{array}{r}20,0 \\
80,0 \\
100,0\end{array}$ & $\begin{array}{r}9 \\
10 \\
19\end{array}$ & $\begin{array}{r}47,4 \\
52,6 \\
100,0\end{array}$ \\
\hline \multirow{2}{*}{$\begin{array}{l}\text { Amigos e família } \\
\text { que vivem perto }\end{array}$} & $55-65$ anos & \begin{tabular}{|l} 
Aumentou \\
Manteve \\
Total
\end{tabular} & $\begin{array}{r}5 \\
24 \\
29 \\
\end{array}$ & $\begin{array}{r}17,2 \\
82,8 \\
100,0 \\
\end{array}$ & $\begin{array}{r}4 \\
11 \\
15 \\
\end{array}$ & $\begin{array}{r}26,7 \\
73,3 \\
100,0 \\
\end{array}$ & $\begin{array}{r}9 \\
35 \\
44 \\
\end{array}$ & $\begin{array}{r}20,5 \\
79,5 \\
100,0 \\
\end{array}$ \\
\hline & $\begin{array}{l}66 \text { ou } \\
\text { mais anos }\end{array}$ & \begin{tabular}{|l} 
Aumentou \\
Manteve \\
Total \\
\end{tabular} & $\begin{array}{r}7 \\
7 \\
14 \\
\end{array}$ & $\begin{array}{r}50,0 \\
50,0 \\
100,0 \\
\end{array}$ & $\begin{array}{l}1 \\
6 \\
7\end{array}$ & $\begin{array}{r}14,3 \\
85,7 \\
100,0 \\
\end{array}$ & $\begin{array}{r}8 \\
13 \\
21 \\
\end{array}$ & $\begin{array}{r}38,1 \\
61,9 \\
100,0 \\
\end{array}$ \\
\hline \multirow{2}{*}{$\begin{array}{l}\text { Pessoas com } \\
\text { quem partilho os } \\
\text { mesmos } \\
\text { interesses } \\
\text { pessoais e } \\
\text { passatempos }\end{array}$} & $55-65$ anos & $\begin{array}{l}\text { Aumentou } \\
\text { Manteve } \\
\text { Não sabe/não responde } \\
\text { Total }\end{array}$ & $\begin{array}{r}8 \\
21 \\
1 \\
30\end{array}$ & $\begin{array}{r}26,7 \\
70,0 \\
3,3 \\
100,0\end{array}$ & $\begin{array}{r}5 \\
10 \\
0 \\
15\end{array}$ & $\begin{array}{r}33,3 \\
66,7 \\
0,0 \\
100,0\end{array}$ & $\begin{array}{r}13 \\
31 \\
1 \\
45\end{array}$ & $\begin{array}{r}28,9 \\
68,9 \\
2,2 \\
100,0\end{array}$ \\
\hline & $\begin{array}{l}66 \text { ou } \\
\text { mais anos }\end{array}$ & $\begin{array}{l}\text { Aumentou } \\
\text { Manteve } \\
\text { Não sabe/não responde } \\
\text { Total }\end{array}$ & $\begin{array}{r}8 \\
6 \\
0 \\
14\end{array}$ & $\begin{array}{r}57,1 \\
42,9 \\
0,0 \\
100,0\end{array}$ & $\begin{array}{l}0 \\
6 \\
1 \\
7\end{array}$ & $\begin{array}{r}0,0 \\
85,7 \\
14,3 \\
100,0\end{array}$ & $\begin{array}{r}8 \\
12 \\
1 \\
21\end{array}$ & $\begin{array}{r}38,1 \\
57,1 \\
4,8 \\
100,0\end{array}$ \\
\hline
\end{tabular}

Nota: Questão de escolha múltipla, pelo que as percentagens são calculadas por referência ao total de indivíduos que escolheram uma ou mais possibilidades de resposta.

mais jovens, homens e mulheres, constata-se uma tendência para a manutenção dos contactos já existentes (ver quadro 6).

O uso pouco frequente quer do computador, quer da internet é uma regularidade presente na amostra estudada, sobretudo entre as seniores mais velhas. Porém, os dados também demonstram que os seniores, em geral, têm consciência da sua utilidade em vários domínios, inclusive ao nível do incremento das relações intergeracionais. A este propósito, Celeste afirma:

É uma coisa que não me interessa muito. Mas, se preciso peço aos meus netos para irem ver. Até quando quero ir ver, por exemplo, onde fica um museu ou uma coisa qualquer peço aos meus netos para ver onde fica a rua. A internet... para quê? Talvez para navegar por esse mundo fora... [67 anos, doméstica] 


\section{Relação dos seniores com os média}

Apesar das tendências acima descritas, de uma forma geral, os seniores têm alguma familiaridade com os média, sejam os mais jovens (55-65 anos), sejam os mais velhos (66 anos e mais).

No caso dos seniores mais jovens, o rádio, a televisão, o gravador, o gira-discos, por exemplo, fazem parte das suas memórias de infância.

O rádio desde sempre, a televisão em casa quando apareceu em Portugal. [...] Gira-discos, gravadores, sei que era daqueles de fita, o gravador. [Maria Almeida, 55 anos, doméstica]

No Brasil sempre houve televisão e rádio. Aqui também já havia televisão. [...] Tinha gira-discos, leitor de cassete. [Manuel Carlos, 59 anos, comerciante]

Apesar de terem conhecimento da existência de tais tecnologias, as dificuldades socioeconómicas da família de origem de alguns entrevistados eram impeditivas do seu acesso.

Na época, em Portugal só existia uma televisão, digamos... numa Casa do Povo [...]. Posso dizer que se pagava na época cinco tostões para se assistir a televisão. Quando ela começou em Portugal, nós não tínhamos televisão em casa como temos hoje. [...] O rádio não ouvia nada também. Não era fácil as pessoas terem um rádio. [José, 58 anos, comerciante]

Em casa nunca tive! Em casa da minha mãe nunca houve rádios, nunca houve dinheiro para rádios nem para essas coisas.... [Dália, 78 anos, reformada]

Porém, após a constituição de família própria, os seniores, sobretudo os mais velhos, passaram a investir na aquisição de tecnologias da informação e da comunicação, como é o caso de Maria Duarte:

Foi o meu marido, ele é que trazia tudo. Ele gosta muito de trazer coisas cá para casa. [...] A televisão também tive muito cedo. Foi quando vieram as primeiras televisões. As primeiras televisões a cores, uma professora que era amiga da minha filha até se admirou de o meu marido já ter cá uma a cores. [90 anos, doméstica]

Subjacente à aquisição das tecnologias da informação e da comunicação por parte dos seniores, encontram-se motivações ligadas a necessidades de lazer, entretenimento e informação. O interesse por programas noticiosos é comum a todos, homens e mulheres. Porém, para as mulheres idosas as telenovelas encontram-se entre os seus programas preferidos.

Entretenho-me muito com as telenovelas. [Celeste, 67 anos, doméstica] 
Gosto de ouvir as notícias... tanto faz na televisão, como na Rádio Renascença. Gosto de ouvir as notícias, isso gosto. [Dália, 78 anos, reformada]

Anecessidade de se manterem mais atualizados leva alguns seniores, sobretudo os mais jovens, a recorrer a outros meios de comunicação social (por exemplo, jornais, revistas, serviços noticiosos, internet).

Revista Visão e jornal diário, [... a par do] telejornal da manhã na televisão. [Manuel Carlos, 59 anos, comerciante]

Hoje eu digo que o tempo está a passar rápido demais e não me sobra tempo para ler o jornal. Então, se eu quero recorro ao Google e ali encontro tudo. Tudo o que eu preciso está lá. É uma das minhas páginas preferidas da internet. [Diva, 56 anos, empregada de limpeza]

Independentemente da idade dos seniores, observa-se uma adesão positiva ao telemóvel. No entanto, os mais jovens adquirem telemóveis tecnologicamente mais equipados e usam-nos com fins mais específicos.

O meu telemóvel tem câmara fotográfica, tem MP3 e tem jogos. Para além das chamadas e das mensagens que são as funções básicas de um telemóvel, utilizo com bastante frequência o MP3. [José, 58 anos, comerciante]

O meu telemóvel é Nokia. Tem uma máquina fotográfica, 3,2 mega. Já é velhinho e vai ser trocado por outro melhor. [...] No meu telemóvel tenho lá 1400 músicas. [Diva, 56 anos, empregada de limpeza)

Os mais velhos optam por telemóveis tecnologicamente menos evoluídos e usam-nos para comunicar com a família e amigos, mas também para resolverem situações-problema.

Não saio sem telemóvel. É o mais simples possível. Gosto de receber chamadas e telefonar. Não muito complicado, nada mais. [Celeste, 67 anos, doméstica]

Eu uso mais para falar com as minhas filhas... é só para falar com a família e os amigos. [Lurdes, 59 anos, reformada)

Agora tenho telemóvel. [...] às vezes telefono para as minhas amigas, às vezes quando vou a qualquer lado telefono para a tua madrinha [da filha] para ela me ir buscar. [Dália, 78 anos, reformada]

Em suma, os seniores mais jovens acabam por explorar outras funções do telemóvel (por exemplo, mensagens, fotografia, ouvir música, consulta da internet), ao contrário dos mais velhos que se ficam principalmente pela utilização das funções de comunicação com a família e os amigos. Revelam, de igual modo, uma maior apetência por telemóveis tecnologicamente mais evoluídos, ao contrário dos seniores mais velhos. 
Quadro 7 Até que ponto seria difícil deixar de ter as seguintes tecnologias da informação e da comunicação (TIC)

\begin{tabular}{|c|c|c|c|c|c|c|c|c|}
\hline \multirow{3}{*}{ TIC } & \multirow{3}{*}{$\begin{array}{l}\text { Escalão } \\
\text { etário }\end{array}$} & \multirow{3}{*}{ Até que ponto } & \multicolumn{4}{|c|}{ Género } & \multirow{2}{*}{\multicolumn{2}{|c|}{ Total }} \\
\hline & & & \multicolumn{2}{|c|}{ Masculino } & \multicolumn{2}{|c|}{ Feminino } & & \\
\hline & & & $\mathrm{N}$ & $\%$ & $\mathrm{~N}$ & $\%$ & $\mathrm{~N}$ & $\%$ \\
\hline \multirow{2}{*}{$\begin{array}{l}\text { Deixar de ter } \\
\text { televisão }\end{array}$} & 55-65 anos & $\begin{array}{l}\text { Muito } \\
\text { Um pouco } \\
\text { Nada } \\
\text { Não uso/Não tenho } \\
\text { Total }\end{array}$ & $\begin{array}{r}11 \\
9 \\
8 \\
1 \\
29\end{array}$ & $\begin{array}{r}37,9 \\
31,0 \\
27,6 \\
3,4 \\
100,0\end{array}$ & $\begin{array}{r}7 \\
8 \\
0 \\
0 \\
15\end{array}$ & $\begin{array}{r}46,7 \\
53,3 \\
0,0 \\
0,0 \\
100,0\end{array}$ & $\begin{array}{r}18 \\
17 \\
8 \\
1 \\
44\end{array}$ & $\begin{array}{r}40,9 \\
38,6 \\
18,2 \\
2,3 \\
100,0\end{array}$ \\
\hline & $\begin{array}{l}66 \text { ou mais } \\
\text { anos }\end{array}$ & $\begin{array}{l}\text { Muito } \\
\text { Um pouco } \\
\text { Total }\end{array}$ & $\begin{array}{r}9 \\
5 \\
14\end{array}$ & $\begin{array}{r}64,3 \\
35,7 \\
100,0\end{array}$ & $\begin{array}{l}3 \\
3 \\
6\end{array}$ & $\begin{array}{r}50,0 \\
50,0 \\
100,0\end{array}$ & $\begin{array}{r}12 \\
8 \\
20\end{array}$ & $\begin{array}{r}60,0 \\
40,0 \\
100,0\end{array}$ \\
\hline \multirow[t]{2}{*}{$\begin{array}{l}\text { Deixar de ter } \\
\text { telemóvel }\end{array}$} & $55-65$ anos & $\begin{array}{l}\text { Muito } \\
\text { Um pouco } \\
\text { Nada } \\
\text { Não uso/Não tenho } \\
\text { Não sabe/Não responde } \\
\text { Total }\end{array}$ & $\begin{array}{r}14 \\
10 \\
4 \\
1 \\
1 \\
30\end{array}$ & $\begin{array}{r}46,7 \\
33,3 \\
13,3 \\
3,3 \\
3,3 \\
100,0\end{array}$ & $\begin{array}{r}9 \\
6 \\
0 \\
0 \\
0 \\
15\end{array}$ & $\begin{array}{r}60,0 \\
40,0 \\
0,0 \\
0,0 \\
0,0 \\
100,0\end{array}$ & $\begin{array}{r}23 \\
16 \\
4 \\
1 \\
1 \\
45\end{array}$ & $\begin{array}{r}51,1 \\
35,6 \\
8,9 \\
2,2 \\
2,2 \\
100,0\end{array}$ \\
\hline & $\begin{array}{l}66 \text { ou mais } \\
\text { anos }\end{array}$ & $\begin{array}{l}\text { Muito } \\
\text { Um pouco } \\
\text { Nada } \\
\text { Total }\end{array}$ & $\begin{array}{r}6 \\
5 \\
3 \\
14\end{array}$ & $\begin{array}{r}42,9 \\
35,7 \\
21,4 \\
100,0\end{array}$ & $\begin{array}{l}5 \\
1 \\
0 \\
6\end{array}$ & $\begin{array}{r}83,3 \\
16,7 \\
0,0 \\
100,0\end{array}$ & $\begin{array}{r}11 \\
6 \\
3 \\
20\end{array}$ & $\begin{array}{r}55,0 \\
30,0 \\
15,0 \\
100,0\end{array}$ \\
\hline
\end{tabular}

Nota: Questão de escolha múltipla, pelo que as percentagens são calculadas por referência ao total de indivíduos que escolheram uma ou mais possibilidades de resposta.

Apesar desta diferença, o telemóvel tem uma grande centralidade na vida quotidiana destas pessoas, sendo para elas muito difícil deixar de possuir esta tecnologia, principalmente para as mulheres (ver quadro 7).

O telemóvel e a televisão são duas das tecnologias mais apontadas como sendo as mais difíceis de deixar de utilizar, tanto pelos seniores jovens como pelos mais velhos, com destaque para as mulheres de ambos os escalões etários. Este resultado demonstra uma adesão maciça dos seniores a estas tecnologias.

\section{Conclusão}

No presente artigo pretendemos analisar a relação dos seniores mais jovens (55-65 anos) e dos mais velhos (66 ou mais anos) com as tecnologias da informação e da comunicação, em particular com o computador e a internet. Também estudámos o tipo de relação que têm com os média, sobretudo com os meios de comunicação de que fazem um uso quotidiano mais frequente, como é o caso da televisão e do telemóvel.

A nossa abordagem metodológica centrou-se principalmente em dados quantitativos descritivos de algumas características sociodemográficas da nossa amostra (91 seniores), mas também da frequência, interesse e finalidades subjacentes ao uso das referidas tecnologias por parte dos seniores. Complementarmente foram utilizados 
dados provenientes de 30 entrevistas semiestruturadas realizadas a famílias residentes em Portugal em 2009.

Os dados apresentados evidenciam, de alguma forma, uma relação entre a idade, o género dos entrevistados e o uso de algumas tecnologias da informação e da comunicação, em particular o telemóvel, o computador e a internet. São, com efeito, os homens seniores, inclusive os mais velhos, que revelam um uso mais frequente do computador e da internet. Apesar de alguns seniores mais jovens ainda usarem a internet por razões profissionais, os mais velhos fazem-no sobretudo por necessidades de pesquisa, obtenção de informação, comunicação, entretenimento, lazer e interação com as gerações mais novas (filhos e netos).

No caso das mulheres, são as idosas mais jovens que utilizam mais frequentemente o computador e a internet, embora por razões distintas das dos homens. Neste escalão etário estas tecnologias são usadas com fins de comunicação e interação com familiares e amigos. É de destacar que algumas das seniores mais jovens que revelam uma maior utilização da internet e do computador ainda se encontram profissionalmente ativas, bem como apresentam níveis de escolaridade ligeiramente superiores aos das mulheres mais velhas.

De qualquer modo, comparativamente são as mulheres que usam pouco o computador e a internet, principalmente as mais velhas. Algumas, devido ao estado avançado de idade, recusam o próprio "conceito" de computador, outras admitem que teriam dificuldades no seu uso. Porém referem que quando têm necessidade de alguma informação solicitam a colaboração de familiares, em particular dos netos.

Tal não sucede entre os seniores do sexo masculino, quer entre os mais jovens, quer entre os mais velhos. Em ambos os casos constata-se um uso mais frequente de ambas as tecnologias, ora por razões profissionais, ora por necessidades e interesses associados à pesquisa, consulta, informação, cultura, lazer, entretenimento e comunicação.

Curiosamente, a relação dos idosos com alguns média é distinta da descrita relativamente ao uso do computador e da internet. Com efeito, a televisão e o telemóvel surgem como os meios de comunicação mais frequentes quer para entretenimento e lazer, quer com o fim de comunicação. O telemóvel é representado como um meio essencial de comunicação com a família e os amigos, desempenhando, de certa forma, uma função de incremento das sociabilidades amicais e intergeracionais. Para os idosos mais velhos, sobretudo as mulheres, os telemóveis devem ser tecnologicamente simples. Ao contrário dos seniores mais jovens que, para além de adquirem telemóveis de gerações tecnologicamente mais avançadas, os usam com vários fins (e.g., comunicação, entretenimento, lazer, navegar na internet).

O interesse pelas tecnologias digitais e o seu uso com finalidades distintas é revelador de um comportamento, por parte de alguns seniores, que se inscreve, como vimos, na noção de formação ao longo da vida, contribuindo assim para a sua inclusão nas sociedades em rede e para o fomento das relações e solidariedades intergeracionais e amicais. Inscreve-se, de igual modo, no conceito de envelhecimento produtivo, na medida em que tais práticas permitem o envolvimento dos seniores em atividades de realização significativas, pessoalmente satisfatórias e com um impacto positivo nas suas vidas e nas dos outros (Kaye, Butter e Webster, 2003). 
Em síntese, subjacentes ao uso das tecnologias digitais por parte dos seniores da nossa amostra encontram-se funções de atualização pessoal e profissional, de comunicação, informação e conhecimento, de pesquisa de serviços, de lazer e entretenimento e de convívio com familiares e amigos. Tais tecnologias são, portanto, um meio de inclusão sociodigital.

Importa, por isso, promover a sua utilização entre os seniores portugueses, sobretudo entre as mulheres idosas que são, como vimos, as que manifestam níveis mais baixos de interesse pelas tecnologias da informação e da comunicação. Este resultado exige, portanto, que estejamos atentos ao "género" da inclusão/exclusão digital nesta fase do ciclo da vida humana.

\section{Referências bibliográficas}

Cardoso, Gustavo, António Firmino da Costa, Cristina Palma Conceição, e Maria do Carmo Gomes (2005), A Sociedade em Rede em Portugal, Porto, Campo das Letras Editores.

Castells, Manuel (2004), A Galáxia Internet, Lisboa, Fundação Calouste Gulbenkian.

Castells, Manuel (2007), A Sociedade em Rede. A Era da Informação, vol. I, Economia, Sociedade e Cultura, Lisboa, Fundação Calouste Gulbenkian.

Costa, António Firmino da, Maria do Carmo Gomes, Patrícia Ávila, e João Sebastião (2000), “Novas análises dos níveis de literacia em Portugal: comparações diacrónicas e internacionais", Actas do IV Congresso Português de Sociologia. Sociedade Portuguesa. Passados Recentes, Futuros Próximos, Lisboa, Associação Portuguesa de Sociologia, pp. 1-12.

Costa, António Firmino da, Cristina P. Conceição, Inês Pereira, Pedro Abrantes, e Maria do Carmo Gomes (2005), Cultura Científica e Movimento Social. Contributo para a Análise do Programa Ciência Viva, Oeiras, Celta Editora.

Dias, Isabel (2005), "Envelhecimento e violência contra os idosos", Sociologia, 15, pp. 249-273.

Doll, Johannes, Adriano Pasqualotti, e Dante A. C. Barone (2007), "As tecnologias de informação e comunicação na vida de idosos com sintomas de depressão: significado, experiências e relacionamentos", Novas Tecnologias na Educação, 5 (2), pp. 1-8.

Esteves, António Joaquim (1995), Jovens e Idosos. Família, Escola e Trabalho, Porto, Edições Afrontamento.

Flick, Uwe (2005), Métodos Qualitativos na Investigação Científica, Lisboa, Monitor.

Fonseca, A. Manuel (2004), O Envelhecimento. Uma Abordagem Psicológica, Lisboa, Universidade Católica Editora.

Ghiglione, Rodolphe, e Benjamin Matalon (2001), O Inquérito. Teoria e Prática, Oeiras, Celta Editora.

Gonçalves, Carlos Manuel, e Isabel Dias (2008), “Envelhecimento e emprego dos trabalhadores mais velhos", Rediteia, revista da Rede Europeia Anti-Pobreza/Portugal, 41, pp. 26-28.

Guionnet, Christine, e Erik Neveu (2005), Féminins/Masculins. Sociologie du Genre, Paris, Armand Colin.

Guillemard, Anne-Marie (2004), “Les sociétés à l'épreuve du vieillissement”, Futuribles, 299, pp. 45-64. 
Henriques, Susana (2011), “Educação social, literacia digital e cidadania: contributos metodológicos", RAE, Revista Animação e Educação, 13, Lisboa, Universidade Aberta, pp. 1-13, disponível em: http://anae.biz/rae/?p=2220

INE (2010), Estatísticas Sociais, Lisboa, INE.

Kaye, Leonard W., Sandra S. Butter, e Nancy M. Webster (2003), “Toward a productive ageing paradigm for geriatric practice, Ageing International, 28 (2), pp. 200-213.

Lima, Izaíra T. S., Samara S. Q. Nogueira, e Taciana L. Burgos (2008), “Inclusão do idoso no mundo digital: realidade mossoroense e cenário brasileiro", XXXI Congresso Brasileiro de Ciências da Comunicação, Natal, 2 a 6 de setembro.

Martin, Inácio, e outros (2007a), "Políticas sociais para a terceira idade", em Agustín Requejo Osório e Fernando Cabral Pinto (coords.), As Pessoas Idosas. Contexto Social e Intervenção Educativa, Lisboa, Instituto Piaget, cap. V, pp. 131-179.

Martin, Inácio, e outros (2007b), “O desenvolvimento do paradigma do envelhecimento produtivo: os novos papéis dos seniores na sociedade", em Agustín Requejo Osóri e Fernando Cabral Pinto (coords.), As Pessoas Idosas. Contexto Social e Intervenção Educativa, Lisboa, Instituto Piaget, cap. VII, pp. 203-223.

Mauritti, Rosário (2004), “Padrões de vida na velhice”, Análise Social, XXXIX (171), pp. 339-363.

Mendes, Fernando Ribeiro (2005), Conspiração Grisalha. Segurança Social, Competitividade e Gerações, Oeiras, Celta Editora.

Paúl, Constança (1997), Lá para o Fim da Vida. Idosos, Família e Meio Ambiente, Coimbra, Almedina.

Pestana, Nuno Nóbrega (2003), Trabalhadores Mais Velhos. Políticas Públicas e Práticas Empresariais. Contributos para Uma Política Nacional de Envelhecimento Activo, Lisboa, Direção-Geral do Emprego e das Relações de Trabalho, Ministério da Segurança Social e do Trabalho (MSST).

Riley, Matilda White (1988), "Forward", em Klaus Warner Shaie e Richard T. Campbell (orgs.), Methodological Issues in Aging Research, Nova Iorque, Spring Publishing.

Tamer, Norma Liliana, e Graciela Petriz (2007), "A qualidade de vida dos idosos", em Agustín Requejo Osório e Fernando Cabral Pinto (coords.), As Pessoas Idosas. Contexto Social e Intervenção Educativa, Lisboa, Instituto Piaget, cap. VI, pp. 181-223.

Vallespir, Jordi, e Mercè Morey (2007), “A participação dos idosos na sociedade: integração vs. segregação", em Agustín Requejo Osório e Fernando Cabral Pinto (coords.), As Pessoas Idosas. Contexto Social e Intervenção Educativa, Lisboa, Instituto Piaget, cap. VIII, pp. 225-251.

\section{Outros documentos}

Contribuição da Comissão Europeia para a II Assembleia Mundial sobre o Envelhecimento (2002), "Resposta da Europa ao envelhecimento da população mundial: promover o progresso económico e social num mundo em envelhecimento", Bruxelas, Comissão Europeia.

Nações Unidas (1982), Plan de Acción Internacional sobre el Envejecimiento, Viena, (Resolução 37/51 de 3 de dezembro de 1982), disponível em: http://www.sld.cu/galerias/pdf/sitios/gericuba/plan_de_accion_internacional_de_v iena_sobre_el_envejecimiento.pdf 
Nações Unidas (2002), Plan de Acción Internacional sobre el Envejecimiento, Madrid (Resolução 57/167 de 18 de dezembro de 2002), disponível em: http://www.paho.org/hr-ecourse-s/assets/_pdf/Module3/Lesson1/M3_L1_9.pdf

Isabel Dias. Socióloga e professora associada com agregação da Faculdade de Letras da Universidade do Porto (FLUP), Departamento de Sociologia. Investigadora do Instituto de Sociologia (FLUP) e do Centro de Ciências Forenses/Cencifor-Portugal. E-mail: mdias@letras.up.pt

\section{Resumo/ abstract/ résumé/ resumen}

O uso das tecnologias digitais entre os seniores: motivações e interesses

O artigo tem como principal objetivo analisar a relação dos seniores mais jovens (55-65 anos) e dos mais velhos (66 ou mais anos) com as tecnologias da informação e da comunicação (TIC), em particular com o computador e a internet. Desenvolve-se uma análise de cariz quantitativo, com base num inquérito por questionário administrado nas cidades de Lisboa, Porto e Coimbra a uma amostra de 792 indivíduos, em complementaridade com alguns dados qualitativos recolhidos através de 30 entrevistas semiestruturadas. Tenta-se conhecer as motivações e interesses ligados ao uso das referidas tecnologias e compreender em que medida tal prática contribui para a inclusão dos mais velhos nas sociedades tecnológicas e incrementa as relações e solidariedades intergeracionais e amicais.

Palavras-chave envelhecimento, tecnologias da informação e da comunicação (TIC).

The use of digital technologies among seniors: motivations and interests

The article has as main objetive to study the relationship of the younger seniors (55-65 years) and older (over 66 years) with information and communication technology (ICT), particularly with computer and internet. It develops an analysis of quantitative nature, based on a survey questionnaire administered in the cities of Lisbon, Porto and Coimbra on a sample of 792 individuals. Addition was made a qualitative analysis based on data collected through 30 semi-structured interviews. We try to understand the motivations and interests related to the use of these technologies and understand to what extent this practice contributes to the inclusion of older people in technological societies and increases solidarity and intergenerational relationships and making new friends.

$\underline{\text { Keywords }}$ aging, information and communication technology (ICT). 
L'utilisation des technologies numériques chez les seniors: motivations et intérêts

L'article a pour objectif principal d'étudier la relation entre les personnes âgées plus jeunes (55-65 ans) et plus âgées (plus de 66 ans) avec les technologies de l'information et de la communication (TIC), notamment avec l'ordinateur et internet. Il développe une analyse de nature quantitative, basée sur un questionnaire d'enquête administré dans les villes de Lisbonne, Porto et Coimbra sur un échantillon de 792 individus. Ajout a été fait d'une analyse qualitative basée sur des données recueillies par 30 entretiens semi-structurés. Nous essayons de comprendre les motivations et les intérêts liés à l'utilisation de ces technologies et à comprendre dans quelle mesure cette pratique contribue à l'inclusion des personnes âgées dans les sociétés technologiques et augmente la solidarité et les relations intergénérationnelles et les relations d'amitié.

Mots-clés vieillissement, technologies de l'information et de la communication (TIC).

El uso de las tecnologías digitales entre los adultos mayores: motivaciones e intereses

El artículo tiene como principal objetivo analizar la relación de los adultos mayores más jóvenes (55-65 años) y de los más viejos (66 o más años) con las tecnologáas de la información y de la comunicación (TIC), en particular con la computadora y la internet. Se lleva a cabo un análisis de carácter cuantitativo, con base en una encuesta por cuestionario administrado en las ciudades de Lisboa, Porto y Coimbra a una muestra de 792 individuos, en complementariedad con algunos datos cualitativos recabados a través de 30 entrevistas semiestructuradas. Se intenta conocer las motivaciones e intereses ligados al uso de las referidas tecnologías y comprender en qué medida tal práctica contribuye para la inclusión de los más viejos en las sociedades tecnológicas e incrementa las relaciones y solidaridades intergeneracionales y fraternales.

Palabras-clave envejecimiento, tecnologías de la información y de la comunicación (TIC). 